Tropical Journal of Pharmaceutical Research January 2019; 18 (1): 145-149

ISSN: 1596-5996 (print); 1596-9827 (electronic)

(C) Pharmacotherapy Group, Faculty of Pharmacy, University of Benin, Benin City, 300001 Nigeria.

\title{
Effect of tirofiban on cardiac function, cardiomyocytes and inflammatory reaction in patients with acute myocardial infarction during emergency percutaneous coronary intervention
}

\author{
Wang Qi-sheng, Zou Li-jun* \\ Emergency Department, Hanchuan Hospital, Hanchuan People's Hospital/Wuhan University People's Hospital, No. 1 People's \\ Boulevard, Hanchuan, Hubei 431600, China
}

*For correspondence: Email: ph1178@163.com

\begin{abstract}
Purpose: To investigate the effect of tirofiban on cardiac function, cardiomyocytes and inflammatory reaction in acute myocardial infarction (AMI) patients during emergency percutaneous coronary intervention (PCl).

Methods: Ninety AMI patients who underwent PCI for two years in Hanchuan Hospital, Hanchuan People's HospitalWuhan University People's Hospital, Hanchuan, China, were involved in this retrospective studies. Two groups were used (46 patients per group). The study group was treated with tirofiban, while the control group was without tirofiban exposure. Changes in brain natriuretic peptide $(B N P)$, left ventricular end systolic diameter (LVESD) and left ventricular end diastolic diameter ( $L V E D D)$ were determined using a biochemical analyzer, while the inflammatory cytokines i.e. interleukin -6 (IL-6), tumor necrosis factor (TNF-) and high sensitive C reactive protein (hs-CRP) were assayed with ELISA kits.

Results: One week after operation, a significantly lower level of BNP and a significantly higher level of $L V E F$ were seen in the study group than in controls $(p<0.05)$. After the operation, the study group had significantly lower levels of CK, CK-MB and cTnl than the control group $(p<0.01)$. Pre-operative IL-6, TNF- $\alpha$ and hs-CRP levels were comparable between both groups $(p>0.05)$, but their post-operative values were significantly lower in the study group than in the control group $(p<0.01)$.

Conclusion: The use of tirofiban for AMI patients undergoing $P C l$ significantly reduces $B N P$, increases $L V E F$, improves cardiac function, protects myocardial cells, reduces the level of inflammatory cytokines, and inhibits inflammatory reactions.
\end{abstract}

Keywords: Percutaneous coronary intervention, Acute myocardial infarction, Tirofiban, Cardiac function

This is an Open Access article that uses a funding model which does not charge readers or their institutions for access and distributed under the terms of the Creative Commons Attribution License (http://creativecommons.org/licenses/by/4.0) and the Budapest Open Access Initiative (http://www.budapestopenaccessinitiative.org/read), which permit unrestricted use, distribution, and reproduction in any medium, provided the original work is properly credited.

Tropical Journal of Pharmaceutical Research is indexed by Science Citation Index (SciSearch), Scopus, International Pharmaceutical Abstract, Chemical Abstracts, Embase, Index Copernicus, EBSCO, African Index Medicus, JournalSeek, Journal Citation Reports/Science Edition, Directory of Open Access Journals (DOAJ), African Journal Online, Bioline International, Open-J-Gate and Pharmacy Abstracts

\section{INTRODUCTION}

Acute myocardial infarction (AMI) is a frequent and critical cardiovascular problem seen in clinics. Acute decrease or stoppage of blood supply caused by coronary artery stenosis or obstruction gives rise to AMl, which leads to myocardial necrosis. The main clinical manifestations of AMI are severe and persistent chest tightness, palpitations, chest pain, and 
arrhythmia or shock [1]. The disease is associated with high frequency of occurrence, unfavorable prognosis and high mortality, and poor quality of life. In recent years, with rapid advances in economy, the lifestyle of people has changed a lot in China, resulting in increasing incidence of AMI.

Emergency percutaneous coronary intervention $(\mathrm{PCl})$ is currently the major therapy for AMI. It is the preferred option for AMI based on the guidelines for AMI. Emergency $\mathrm{PCl}$ restores vessel recanalization in a short time, effectively reduces mortality and relapse rate of infarction, improves microcirculatory blood flow and cardiac function, and shortens the length of hospital stay [2-4]. Some studies have revealed that the use of tirofiban in emergency $\mathrm{PCl}$ can enhance clinical outcomes and safety [5]. However, it is not clear whether it affects postoperative cardiac function, myocardial cells and inflammatory response of patients.

This study was aimed at investigating the influence of tirofiban on postoperative cardiac function, myocardial cells and inflammatory response in patients with AMI undergoing emergency $\mathrm{PCl}$.

\section{METHODS}

\section{General characteristics of the patients}

A retrospective study was carried out on 90 AMI patients who underwent emergency $\mathrm{PCl}$ on admission to the Cardiology Department of Hanchuan Hospital, Hanchuan People's Hospital/Wuhan University People's Hospital, Hanchuan, China from January 2015 to December 2017. Diagnosis of AMI was in accordance with the Diagnosis and Treatment Criteria of $A M I[6]$.

Inclusion criteria: The included patients were those diagnosed with $\mathrm{AMI}$ in the clinic, and who were aged from 45 to 68 years, with presentations consistent with emergency $\mathrm{PCl}$ indication, and with onset time $<4 \mathrm{~h}$.

Exclusion criteria: Subjects with PCl intolerance, severe liver and kidney dysfunction, malignant tumors, severe anemia, poor compliance, and mental disorder, were excluded. Two classes of patients were studied: those exposed to tirofiban (observation group) and patients who were not treated with tirofiban (these served as controls), with 45 subjects/group. The observation group comprised 23 men and 22 women with mean age of $57.4 \pm 5.2$ years, and mean disease course of $115 \pm 51 \mathrm{~min}$. There were 17 patients with hypertension, 8 with diabetes, and 11 smokers. In the control group, there were 24 males and 21 females aged between 46 to 67 years (mean age $=58.6 \pm 5.4$ years), with mean disease course of $122 \pm 57 \mathrm{~min}$. The control group had 15 patients with hypertension, 9 with diabetes, and 13 smokers. There were no statistical differences in general clinical data/biodata i.e., sex, age, disease course, hypertension, diabetes and smoking between two groups ( $p>0.05)$. All patients signed informed consent form. This study received approval from the Ethical Committee of Hanchuan Hospital, Hanchuan People's Hospital and Wuhan University People's Hospital, Hanchuan City, China. (approval no. = 201810292). The study was conducted in line with the provisions in Helsinki Declaration promulgated in 1964 as amended in 1996 [7].

\section{Treatment}

At admission, all patients were given aspirin enteric-coated tablets (Sinopharm Shantou Jinshi Pharmaceutical Co. Ltd, H44025065), 300 mg po, and clopidogrel hydrogen sulfate tablets (Sinofi Pharmaceutical Co. Ltd, J20130083), 600 $\mathrm{mg}$ po. For the patients in the observation group, tirofiban (Hangzhou Zhongmei Huadong Medicine Co. Ltd, H20060265) was injected at 10 $\mu \mathrm{g} / \mathrm{kg}$ into their coronary arteries during $\mathrm{PCl}$, along with i.v. infusion of $0.15 \mu \mathrm{g} /(\mathrm{kg} / \mathrm{min})$ for 24 - 36 h. Both groups were treated with conventional drugs and $\beta$-blockers. Statins and angiotensin receptor antagonists were used depending on the patient's condition.

\section{Therapeutic and biochemical indicators}

The following indicators of patients were determined before, and one week after surgery using color Doppler echocardiography: cardiac function indicators i.e. BNP, LVESD, LVEDD and LVEF. Myocardial-related indicators (CK, CK-MB and cTnl) were determined with automatic biochemical analyzer. The inflammatory cytokines (IL-6, TNF- $\alpha$ and hs-CRP, LVESD, LVEDD and LVEF) were determined using ELISA kits.

\section{Statistical analysis}

All data were collected and then completely input into the research database after statistics. The data were analyzed using software SPSS 21.0. Enumeration data are presented as ratio, and were compared using $x^{2}$ test. Measurement data are presented as mean \pm standard deviation, and comparison between the two groups was done using $t$-test. Values of $p<0.05$ were taken as statistically significant. 


\section{RESULTS}

\section{Cardiac function}

As shown in Table 1, the pre-surgery levels of BNP, LVESD, LVEDD and LVEF in the two groups were comparable $(p>0.05)$. However, there were significant improvements in these cardiac function parameters after surgery: BNP was significantly lower in the tirofiban-treated patients than in controls, while the tirofiban treatment led to significant increase in LVEF, when compared with controls $(p<0.05)$. There were no significant differences in LVESD and LVEDD between the two groups $(p>0.05)$.

Table 1: Cardiac function indicators in the two groups (mean $\pm \mathrm{SD}, \mathrm{n}=45$ )

\begin{tabular}{llcccc}
\hline Group & Time & $\begin{array}{c}\text { BNP } \\
(\mathbf{p g} / \mathbf{m L})\end{array}$ & $\begin{array}{c}\text { LVESD } \\
(\mathbf{m m})\end{array}$ & $\begin{array}{c}\text { LVEDD } \\
(\mathbf{m m})\end{array}$ & $\begin{array}{c}\text { LVEF } \\
(\%)\end{array}$ \\
\hline \multirow{4}{*}{ Study } & Before & $1261.4 \pm$ & $39.6 \pm$ & $56.7 \pm$ & $44.6 \pm$ \\
& surgery & 157.9 & 5.2 & 4.3 & 5.3 \\
& After & $352.7 \pm$ & $33.9 \pm$ & $52.8 \pm$ & $51.2 \pm$ \\
& surgery & $43.4^{\star}$ & $4.9^{\star}$ & $3.6^{\star}$ & $7.1^{\star}$ \\
& Before & $1485.7 \pm$ & $39.1 \pm$ & $56.9 \pm$ & $44.9 \pm$ \\
Control & surgery & 168.2 & 5.3 & 4.1 & 5.4 \\
& After & $551.6 \pm$ & $34.6 \pm$ & $53.2 \pm$ & $47.7 \pm$ \\
& surgery & $84.7^{\#^{*}}$ & $5.4^{*}$ & $3.7^{*}$ & $6.8^{\#^{*}}$ \\
\hline
\end{tabular}

${ }^{\star} p>0.05$, relative to the preoperative value, $\# p>0.05$, relative to control group

\section{Myocardium-related indicators}

There were no significant differences in $\mathrm{CK}$, CK$\mathrm{MB}$ and $\mathrm{cTnl}$ in the two groups before surgery ( $p$ $>0.05)$. As shown in Table 2, the levels of myocardial-related indicators in the two groups were improved after surgery, with statistical differences between the preoperative and the postoperative values $(p>0.05)$. After surgery, $\mathrm{CK}, \mathrm{CK}-\mathrm{MB}$ and $\mathrm{cTnl}$ levels were significantly lower in the observation group than in the control group $(p>0.05)$.

\section{Inflammatory cytokines}

The pre-operation values of IL-6, TNF- $\alpha$ and hsCRP were comparable between tirofiban-treated group and the control group $(p>0.05)$. In contrast, the levels of inflammatory cytokines were significantly improved after surgery $(p<$ 0.01; Table 3). Moreover, IL-6, TNF- $\alpha$ and hsCRP levels were significantly lower in the tirofiban-treated patients than in the controls $(p>$ 0.05).

\section{DISCUSSION}

Acute myocardial infarction (AMI) is a cardiovascular disease resulting from acute myocardial ischemia due to coronary vascular occlusion caused by aggregation of platelet due to a variety of factors. The key in treating AMI is to lessen the area of vascular infarction and dredge the infarct-related artery as soon as possible, thereby restoring myocardial blood supply and reducing irreversible myocardial necrosis [8]. The sooner the dredging is effected, the better the outcome. In clinics, emergency PCl is the preferred therapy for $\mathrm{AMI}$, and it has better effectiveness than thrombolysis or other conservative treatments [4].

Table 2: Myocardium-related indicators for the two groups (mean $\pm S D, N=45$ )

\begin{tabular}{lcccccc}
\hline \multirow{2}{*}{ Group } & \multicolumn{2}{c}{$\mathrm{CK}(\boldsymbol{\mu g} / \mathrm{mL})$} & \multicolumn{2}{c}{ CK-MB $(\boldsymbol{\mu g} / \mathrm{mL})$} & \multicolumn{2}{c}{$\mathbf{c T n l}(\boldsymbol{\mu g} / \mathbf{m L})$} \\
\cline { 2 - 7 } & Before surgery & After surgery & $\begin{array}{c}\text { Before } \\
\text { surgery }\end{array}$ & After surgery & $\begin{array}{c}\text { Before } \\
\text { surgery }\end{array}$ & After surgery \\
\hline Study & $257.61 \pm 28.43$ & $131.62 \pm 16.58$ & $34.73 \pm 6.45$ & $18.61 \pm 5.32$ & $31.52 \pm 5.21$ & $19.84 \pm 3.47^{\circ}$ \\
Control & $259.73 \pm 26.39$ & $172.24 \pm 19.67^{*}$ & $36.64 \pm 6.29$ & $22.74 \pm 5.87^{*}$ & $32.74 \pm 5.11$ & $27.62 \pm 3.85^{*}$ \\
$T$ & 0.366 & 10.592 & 1.422 & 3.497 & 1.122 & 10.069 \\
$P$ & 0.715 & 0.001 & 0.159 & 0.001 & 0.265 & 0.001 \\
\hline$p>0.01$, relative to value before surgery
\end{tabular}

Table 3: Levels of inflammatory cytokines in the two groups (mean $\pm S D, N=45$ )

\begin{tabular}{lcccccc}
\hline \multirow{2}{*}{ Group } & \multicolumn{2}{c}{$\mathrm{IL-6}(\boldsymbol{\mu g} / \mathbf{m L})$} & \multicolumn{2}{c}{ TNF- $\alpha(\mathbf{p g} / \mathbf{m L})$} & \multicolumn{2}{c}{$\mathbf{h s - C R P ~}(\boldsymbol{\mu g} / \mathbf{m L})$} \\
\cline { 2 - 7 } & $\begin{array}{c}\text { Before } \\
\text { surgery }\end{array}$ & $\begin{array}{c}\text { After } \\
\text { surgery }\end{array}$ & $\begin{array}{c}\text { Before } \\
\text { surgery }\end{array}$ & $\begin{array}{c}\text { After } \\
\text { surgery }\end{array}$ & $\begin{array}{c}\text { Before } \\
\text { surgery }\end{array}$ & $\begin{array}{c}\text { After } \\
\text { surgery }\end{array}$ \\
\hline Study & $47.61 \pm 8.42$ & $31.21 \pm 6.57$ & $49.73 \pm 6.34$ & $38.86 \pm 5.14$ & $15.73 \pm 3.36$ & $9.58 \pm 2.15$ \\
Control & $48.94 \pm 8.37$ & $37.16 \pm 6.92^{*}$ & $48.61 \pm 6.29$ & $43.54 \pm 6.51$ & $15.87 \pm 3.42$ & $11.74 \pm 2.86^{*}$ \\
$T$ & 0.752 & 4.183 & 0.841 & 3.785 & 0.196 & 4.050 \\
$P$ & 0.454 & 0.001 & 0.403 & 0.001 & 0.845 & 0.001 \\
\hline
\end{tabular}

${ }^{\star} P>0.01$, compared with the preoperative value 
However, small amounts of thrombus may be detached during $\mathrm{PCl}$, leading to microcirculation embolization; at the same time, surgical instruments may cause vascular endothelial injury which aggravates inflammatory reactions and affects myocardial cell reperfusion [9-11].

These issues can be mitigated through antithrombotic or intensive anticoagulant therapy, thereby enhancing the effectiveness of emergency PCl [5]. Tirofiban, a platelet GPIIb/IIla receptor antagonist, inhibits platelet aggregation and prevents thrombosis [12]. It has been revealed that the use of tirofiban in AMI (involving ST-segment elevation) prior to emergency $\mathrm{PCl}$ resulted in improvement of cardiac function, with good safety [13]. In addition, using tirofiban before $\mathrm{PCl}$ can enhance cardiac function in patients with $\mathrm{AMI}$, and it has been shown to protect vascular endothelium and restore coronary blood flow [14]. It has also been demonstrated that the use of tirofiban in AMI patients undergoing emergency $\mathrm{PCl}$ can ameliorate distal embolism and micro-circulatory disorder.

Brain natriuretic peptide (BNP) is generated from myocardial cells. The synthesis and secretion of BNP rise with increase in chamber wall tension, resulting in elevation of serum BNP levels. Thus, BNP reflects the severity of myocardial ischemia in patients, and so it is one of the indicators of cardiac function. The findings in this study reveal that BNP and LVEF were comparable between both groups one week after surgery, and the level of BNB was much lower in the tirofibantreated patients than in patients who were not exposed to the drug. However, LVEF was much higher in the tirofiban-treated group than in the controls. There were no significant differences in LVESD and LVEDD between both groups one week after surgery. This indicates that the use of tirofiban in emergency $\mathrm{PCl}$ improves the cardiac function of AMI patients. These results are consistent with those reported by other investigators [15].

Creatine kinase (CK) and CK-MB are important myocardial enzymes, and $\mathrm{CK}$ is involved in the regeneration of adenosine triphosphate (ATP) which can regulate intracellular ATP concentrations. The CK-MB is found mainly in myocardial cells. To some extent, it is an important indicator of myocardial damage, and so it used for the diagnosis of AMI. The cTnl is used to assess the area of myocardial infarction due to the fact that it is specific to the myocardium, and it is also very sensitive. Thus, it is an ideal myocardial infarction indicator. Prior to surgery, the levels of CK, CK-MB and CTnl were comparable between the tirofiban-treated patients and controls, suggesting that the severity of myocardial damage in both groups were similar. In contrast, one week after surgery, these parameters were much lower in the tirofiban-treated group, showing significant decreases in the number of apoptotic myocardial cells.

It has been revealed that patients with acute coronary syndrome have significant inflammatory response, suggesting an association with arrhythmia [16]. Some studies have shown that tirofiban inhibits inflammatory cytokines and reduces inflammatory response [17]. The results of this study revealed no significant differences in TNF- $\alpha, \quad I I-6$ and hs-CRP between two groups before surgery. However, one week after surgery, the levels of inflammatory cytokines were significantly reduced in the two groups, relative to preoperative values, and the levels of TNF- $\alpha$, IL- 6 and hs-CRP were much lower in the tirofiban-treated patients than in controls. These results indicate that tirofiban markedly ameliorated inflammatory response in AMI patients after emergency $\mathrm{PCl}$.

\section{CONCLUSION}

The application of tirofiban for AMI patients during emergency $\mathrm{PCl}$ significantly reduces BNP level, elevates LVEF level, enhances cardiac function, protects myocardial cells, reduces inflammatory cytokines, and inhibits inflammatory responses.

\section{DECLARATIONS}

\section{Conflict of Interest}

No conflict of interest associated with this work.

\section{Contribution of Authors}

We declare that this work was done by the author(s) named in this article and all liabilities pertaining to claims relating to the content of this article will be borne by the authors. All authors read and approved the manuscript for publication. Zou Li-jun conceived and designed the study; Wang Qi-sheng, Zou Li-jun collected and analysed the data, while Wang Qi-sheng wrote the manuscript.

\section{REFERENCES}

1. Zhang $Y$. Effect of tirofiban on electrocardiogram of acute St segment elevation myocardial infarction with ischemic $J$ wave. Contemporary Med 2018; 3(12): 92-93. 
2. Zhou $M$, Yu K, Wang $X H$, Yang CS, Lei YP, Wang YG, Xue YZ, Yao HC, Gao B. Analysis on application timing of IABP in emergency $\mathrm{PCl}$ treatment of patients with combined acute myocardial infarction and cardiac shock. Eur Rev Med Pharmacol Sci 2017; 21(12): 29342939.

3. He SH, Yuan B, Ji J, Zhang J, Chen S, Li YM. Analysis on the risk factors for occurrence of electrical storm in percutaneous coronary intervention and its treatment. Chin J Emergency Med 2014; 23(4): 429-432.

4. Zhu LN, Chen D, Chen T, Lin Y, Xu D, Liu L. Efficacy and safety of rt-PA intravenous thrombolysis for treating acute ischemic stroke beyond the therapeutic window: a Meta-analysis. Zhongguo yi shi xie hui 2016; 16(2): 6470.

5. Huang JZ, Yan H, Lu YG, Chen L, Chen LY, He DM. Effect of intracoronary injection of tirofiban for patients with acute myocardial infarction after percutaneous coronary intervention. Chin J Clin Pharmacol 2012; 28(7): 487-489.

6. Chinese Society of Cardiology. Guidelines for diagnosis and treatment of acute myocardial infarction. Chin $J$ Cardiol 2001; 16(12): 710-725.

7. World Health Organization. Declaration of Helsinki. $\mathrm{Br}$ Med J 1996; 313(7070): 1448-1449.

8. Lu JQ, He GX, Pan CX, Wen ZH, Zhang YK, Fang XM, Guo TH, Pan AP, Wu HS. Effect of Anxin granules combined with tirofiba on patients with acute myocardial infarction after elective percutaneous coronary intervention. China J Chin Mater Med 2014; 39(5): 920924.

9. Cannon $C P$. Facilitated $P C l$ in patients with $S T$-elevation myocardial infarction. New England J Med 2008; 358(21): 2205-2217.

10. Sedlis SP, Hartigan PM, Teo KK, Maron DJ, Spertus JA, Mancini GB, Kostuk W, Chaitman BR, Berman D, Lorin
$J D$, et al. Effect of $\mathrm{PCl}$ on long-term survival in patients with stable ischemic heart disease. N Engl J Med 2015; 373(20): 1937-1946.

11. Zhao Y, Chen YD, Tian F, Wang C, Hu S, Wang J, Yang $J$. Predictors of the no-reflow phenomenon after primary percutaneous coronary intervention for acute myocardial infarction. J Southern Med Univ 2012; 32(2): 261-264.

12. Zhou Y, Xue F. The Efficacy of early using Tirofiban on heart function in patients with acute ST-segment elevated myocardial infarction accepted $\mathrm{PCl}$ and its safety. Chin J Arterioscler 2015; 23(9): 907-910.

13. $L i J R, L i Y T$. Effects of preoperative application of Tirofiban on related indexes of patients with acute myocardial infarction. Chin Pharm 2017; 28(20): 28232826.

14. Stone GW, Grines CL, Cox DA, Garcia E, Tcheng JE, Griffin JJ, Guagliumi G, Stuckey T, Turco M, Carroll JD, et al. Comparison of angioplasty with stenting, with or without abciximab, in acute myocardial infarction. $N$ Engl J Med 2002; 346(13): 957.

15. Gao H, Duan XC, Li N. Effect of Tirofiban on the prognosis of heart function and B-type brain natriuretic peptide levels of acute myocardial infarction patients received primary percutaneous coronary artery interventional therapy. Chin Gen Prac 2012; 15(6): 618621.

16. Li SJ. Clinical Effiect of Compound Danshen Dropping Pills Combined with Rosuvastatin or Rosuvastatin Only in the Treatment of Coronary Heart Disease Complicated with Hyperlipidemia. J Math Med 2017; 11 : 1663-1664.

17. Liu YF, Zhang BC, Wen CM, Wen GL. Clinical observation of tirofiban hydrochloride combined with extract of ginkgo biloba leaves in the treatment of patients with acute cerebral infarction. Chin J Pract Nervous Dis 2018; 10: 1063-1068. 